\title{
Foam Stability Related to Polymer Permeability. I. Low Molecular Weight Additives
}

\author{
R. H. B. BOUMA, ${ }^{1}{ }^{*}$ W. J. NAUTA, ${ }^{1}$ J. E. F. ARNAUTS, ${ }^{2}$ Th. VAN DEN BOOMGAARD, ${ }^{1}$ J. M. STEUTEN, ${ }^{2+}$ \\ H. STRATHMANN ${ }^{1}$ \\ ${ }^{1}$ University of Twente, Department of Chemical Technology, P.O. Box 217, NL-7500 AE Enschede, The Netherlands \\ ${ }^{2}$ DSM Research, Polymeric Construction Materials, P.O. Box 18, NL-6160 MD Geleen, The Netherlands
}

Received 17 October 1996; accepted 25 February 1997

\begin{abstract}
In the production of polyethylene foams by extrusion with alkanes as a blowing agent, significant changes in the dimensions of extruded products are encountered. The dimensional stability of a foam with a structure of closed cells is improved by blending the polymer with small amounts of a low molecular weight additive. It is believed that the dimensional stability is related to the ratio of the blowing agent to air permeability. It is shown in this article that the additive reduces the blowing agent permeability more than it does the air permeability only if the additive has migrated to the surface of the polymer. The presence of the additive at the polymer surface has been confirmed by electron microscopy and infrared spectroscopy. The (partially) ordening of the additive at the surface, as shown with wide-angle X-ray diffraction, explains the low gas permeabilities of the additive compared to the corresponding permeabilities of polyethylene. (C) 1997 John Wiley \& Sons, Inc. J Appl Polym Sci 65: 26792689, 1997
\end{abstract}

Key words: foam (extrusion); polyethylene; polymer additive; permeability

\section{INTRODUCTION}

In foam extrusion, there has been a considerable effort directed toward the replacement of ( $\mathrm{H}) \mathrm{CFCs}$ by environmentally friendlier blowing agents. For low-density foams (i.e., foam densities below $100 \mathrm{~kg} / \mathrm{m}^{3}$ ), this now has resulted in the use of isobutane as a blowing agent. The main problem that can occur when foaming with isobutane, postextrusion shrinkage, has been solved by using specific additives that influence the air/ blowing agent exchange in the foam. ${ }^{1}$

Correspondence to: Th. van den Boomgaard (a. vandenboomgaard@ct.utwente.nl).

* Present address: TNO-PML, P.O. Box 45, NL 2280 AA Rijswijk, The Netherlands.

Present address: Avery Dennison, Automotive Division, Trading Estate, Motherwell Way, Grays, Essex, RM20 3XD, UK.

Journal of Applied Polymer Science, Vol. 65, 2679-2689 (1997)

(C) 1997 John Wiley \& Sons, Inc.

CCC 0021-8995/97/132679-11
Understanding of the function of the additives was the objective of this study. Low-density polyethylene (LDPE) was used as the polymer, because it shows severe volumetric changes in foam extrusion with alkanes as blowing agents. ${ }^{2}$ Permeability measurements were performed with LDPE films, blended with certain amounts of stearyl stearamide. Gases used are isobutane and air. Heat treatment, which is shown to influence the gas permeabilities, does lead to analysis of the polymer films with scanning electron microscopy, infrared spectroscopy, and wide-angle X-ray diffraction. In the following article, the dimensional stability of foams will be discussed. ${ }^{3}$

\section{EXPERIMENTAL}

\section{Film Preparation}

Low-density polyethylene (LDPE), Stamylan from DSM (NL), is blended with stearyl steara- 
Table I Isobutane and Air Permeabilities at $30^{\circ} \mathrm{C}$ of As-Prepared and Heat-Treated LDPE Films

\begin{tabular}{ccccc}
\hline & \multicolumn{2}{c}{ Not Treated } & \multicolumn{2}{c}{ With Heat Treatment } \\
\cline { 2 - 4 } $\begin{array}{c}\text { Additive } \\
(\mathrm{w} / \mathrm{w})\end{array}$ & $\begin{array}{c}P_{\text {isobutane }} \\
\text { (barrer) }\end{array}$ & $\begin{array}{c}P_{\text {air }} \\
\text { (barrer) }\end{array}$ & $\begin{array}{c}P_{\text {isobutane }} \\
\text { (barrer) }\end{array}$ & $P_{\text {air }}$ \\
0.00 & 14.7 & 1.1 & 14.7 & 1.6 \\
0.01 & 16.0 & 1.5 & 9.7 & 0.9 \\
0.02 & 14.7 & 1.1 & 4.3 & 0.9 \\
0.05 & 13.3 & 1.0 & 6.3 & \\
\hline
\end{tabular}

Films are blended with an indicated weight fraction $w$ of stearyl stearamide. Thickness of the films is $100-120 \mu \mathrm{m} .1 \mathrm{barrer}$ $=10^{-10}\left\{\left[\mathrm{~cm}^{3}(\mathrm{STP}) \mathrm{cm}\right] /\left[\mathrm{cm}^{2} \mathrm{~s} \mathrm{cmHg}\right]\right\}$.

mide, Kemamide S-180 from Witco Chemicals (U.S.A.), with the help of a twin-screw extruder. The melt flow index of LDPE is $2 \mathrm{~g}$ per $10 \mathrm{~min}$ (at $190^{\circ} \mathrm{C}$ and $5 \mathrm{~kg}$ load) and the density is 921 $\mathrm{kg} \mathrm{m}^{-3}$. The melting point of stearyl stearamide was determined to be $93^{\circ} \mathrm{C}$. Films are made by compression molding of the extruded blend of LDPE and stearyl stearamide for $5 \mathrm{~min}$ at $160^{\circ} \mathrm{C}$ with an applied weight of $2-5$ tons. Films are cooled, while at the same time a weight of 50 tons is applied for another $5 \mathrm{~min}$. In this way, obtained films have a thickness of $100-120 \mu \mathrm{m}$ and contain $0,1,2$, or 5 wt \% stearyl stearamide. Stearyl stearamide content compares with the amount of additive needed to produce dimensionally stable foams.

\section{Permeability Measurements}

Gas permeabilities of the LDPE films are determined in so-called time-lag permeation experiments. In this setup, permeabilities and diffusion coefficients can be obtained. The polymer film is clamped into a test cell. Both the feed and perme- ate side are evacuated to remove all gas molecules from the film. At time $t=0$, a gas with a pressure $p_{1}$ is applied at the upstream side of the film. At the same time, the vacuum pump is disconnected from the downstream side. Due to the pressure difference across the film, gas molecules will sorb at the upstream side of the film and diffuse through the film where they desorb from the downstream side. The gas flow is determined by monitoring the pressure $p_{2}$ as a function of time in the calibrated volume $V_{c}$ connected to the downstream side of the film. Mathematics of the timelag permeation experiment were described by Crank. ${ }^{4}$ After a certain time, there will be a constant increase of the pressure with time. The volume flux $J$ through the film is given by

$$
J=\frac{P\left(p_{1}-p_{2}\right)}{L} \quad t \geq \frac{L^{2}}{3 D}
$$

Here, $P$ is the permeability; $D$, the diffusion coefficient of the gas in the polymeric film; $t$, the time; $p$, the pressure, and $L$, the film thickness. Sub-

Table II Isobutane and Air Diffusion Coefficients at $30^{\circ} \mathrm{C}$ in As-Prepared and Heat-Treated LDPE Films Obtained from Time-Lag Experiments

\begin{tabular}{lcccc}
\hline & \multicolumn{2}{c}{ Not Treated } & & \multicolumn{2}{c}{ With Heat Treatment } \\
\cline { 2 - 3 } \cline { 5 - 6 } $\begin{array}{c}\text { Additive } \\
(\mathrm{w} / \mathrm{w})\end{array}$ & $\begin{array}{c}D_{\text {isobutane }} \\
\left(\mathrm{cm}^{2} \mathrm{~s}^{-1} 10^{8}\right)\end{array}$ & $\begin{array}{c}D_{\text {air }} \\
\left(\mathrm{cm}^{2} \mathrm{~s}^{-1} 10^{8}\right)\end{array}$ & & $\begin{array}{c}D_{\text {isobutane }} \\
\left(\mathrm{cm}^{2} \mathrm{~s}^{-1} 10^{8}\right)\end{array}$ \\
\hline 0.00 & 4.8 & 72 & 4.8 & $\begin{array}{c}D_{\text {air }} \\
\left(\mathrm{cm}^{2} \mathrm{~s}^{-1} 10^{8}\right)\end{array}$ \\
0.01 & 4.1 & 67 & 3.2 & 72 \\
0.02 & 3.1 & 60 & 1.9 & 55 \\
0.05 & 2.9 & 67 & 1.4 & 67 \\
\hline
\end{tabular}

Films are blended with an indicated weight fraction $w$ of stearyl stearamide. Thickness of the films is $100-120 \mu \mathrm{m}$. 


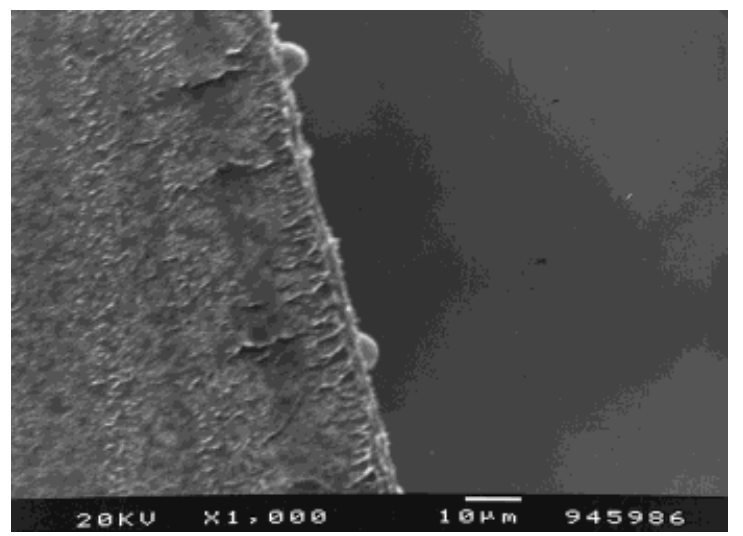

Figure 1 Electron microscope picture of cross section of LDPE blended with 5 wt \% stearyl stearamide. The film was heated for $1 \mathrm{~h}$ at $83^{\circ} \mathrm{C}$.

scripts 1 and 2 refer to the upstream and downstream sides of the film.

The pressure increase in the downstream compartment is related to the volume flux in eq. (1) using the ideal gas law. Knowing the exact volume of the downstream compartment $\left(V_{c}\right)$ and the film area $A$, available for permeation, the volume flux can be calculated with eq. (2):

$$
J=\frac{\frac{d p_{2}}{d t} V_{c} V_{m}(\mathrm{STP})}{\mathrm{RTA}}
$$

where $V_{m}(\mathrm{STP})$ is the molar volume at standard temperature and pressure.

In a steady-state condition, i.e., $d p_{2} / d t$ is constant, the diffusion coefficient $D$ of the permeant can be obtained from the intersection by linearly extrapolating to $p_{2}=0$. The gas permeability $P$ can be calculated from eq. (1).

In Table I, the obtained permeabilities of isobutane and air through the blended films are given with and without heat treatment for $1 \mathrm{~h}$ at $83^{\circ} \mathrm{C}$. Permeabilities are determined at absolute upstream pressures of 4 bar, film thicknesses of $100-120 \mu \mathrm{m}$, and a temperature of $30^{\circ} \mathrm{C}$. From Table I, it is clear that isobutane permeabilities are always larger than are air permeabilities. Blending LDPE alone with the additive stearyl stearamide has no effect on both the isobutane and air permeabilities compared to the unblended film. After heat treatment, however, of $1 \mathrm{~h}$ at $83^{\circ} \mathrm{C}$, a tremendous decrease in the isobutane permeabilities is noticed, whereas the effect on the air permeabilities is negligible. The isobutane permeability decreases by a factor 23 by blending it with only $1-5$ wt $\%$ of stearyl stearamide. The possible mechanism of the reduction of isobutane permeability by blending the polymer with an additive will be discussed later.

In general, both diffusion and solubility contribute to permeability. At $30^{\circ} \mathrm{C}$, pure LDPE is in the rubbery state and permeation is expected to take place through amorphous material. ${ }^{5}$ Differences in permeation behavior for different gases will then be controlled by the difference in solubility. To know which effect is responsible for the observed decrease in isobutane permeability, the solubility or the diffusion coefficient of this component should be measured. The latter property can be determined in a time-lag permeation experiment. The solubility $S$ can be calculated according to

$$
P=D \times S
$$

Although permeabilities represent an intrinsic value, analysis of time lag in a permeation experiment may not give true diffusion coefficients, since the application of eq. (1) is valid for homogeneous films only. With reserve, the calculated diffusion coefficients in heat-treated films are presented in Table II, together with true diffusion coefficients in as-prepared films. One can see that the diffusion coefficient of air, like its permeability, is hardly influenced by blending LDPE with stearyl stearamide. The diffusion coefficient of isobutane decreases with an increasing amount of stearyl stearamide. This effect is stronger after heat treatment. Films with 2 and 5 wt $\%$ of stearyl stearamide have diffusion coefficients that are, respectively, a factor 1.5 and 2 lower for the heattreated films than for the corresponding as-prepared films.

These results indicate that the decrease in permeability of the foam blowing agent is due to a decrease in diffusivity of this component in the film. However, this decrease will only occur after a certain heat treatment was applied to the sample.

The reason for this behavior has not been clarified yet. After the heat treatment, the initially transparent films became hazy. Similar results have been obtained in the work of Frisch et al., ${ }^{6}$ in which a protective thin surface film was introduced at the polymer surface of a polyurethane and a polyethylene film, causing a decrease of both permeability and diffusivity of the penetrant. A theoretical approach of this problem was given by Frisch. ${ }^{7}$ The blooming might be due to phase separation of the two components. To understand 

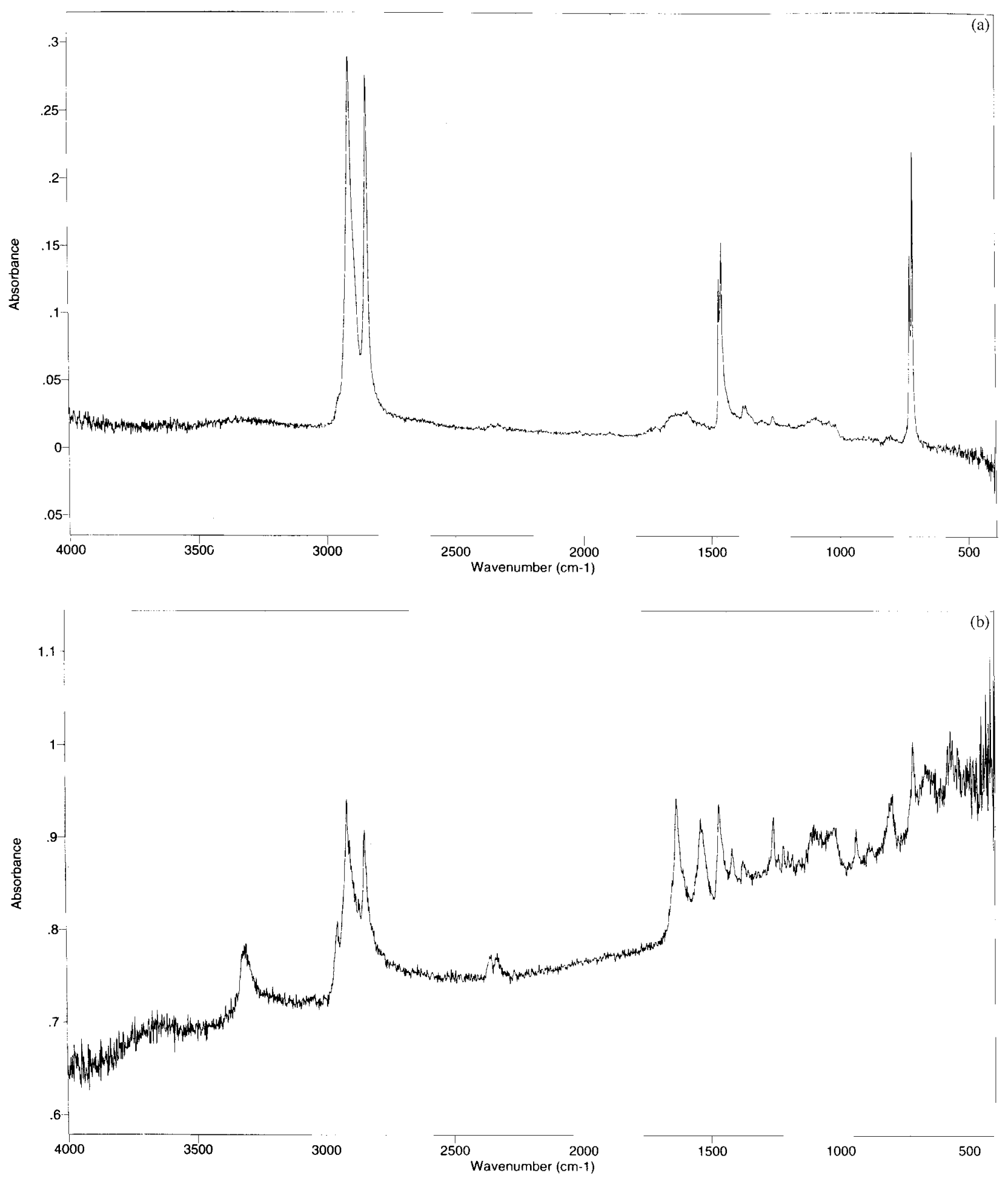

Figure 2 Infrared spectra measured in ATR geometry, with a KRS-5 crystal, and an angle of incidence of $45^{\circ}$. The spectrum of infrared absorbance of (a) an LDPE film, (b) a pressed stearyl stearamide bar, (c) an LDPE film blended with 5 wt \% stearyl stearamide, which has had no heat treatment, and (d) an LDPE film blended with 5 wt $\%$ stearyl stearamide, which has had a heat treatment of $1 \mathrm{~h}$ at $83^{\circ} \mathrm{C}$. 

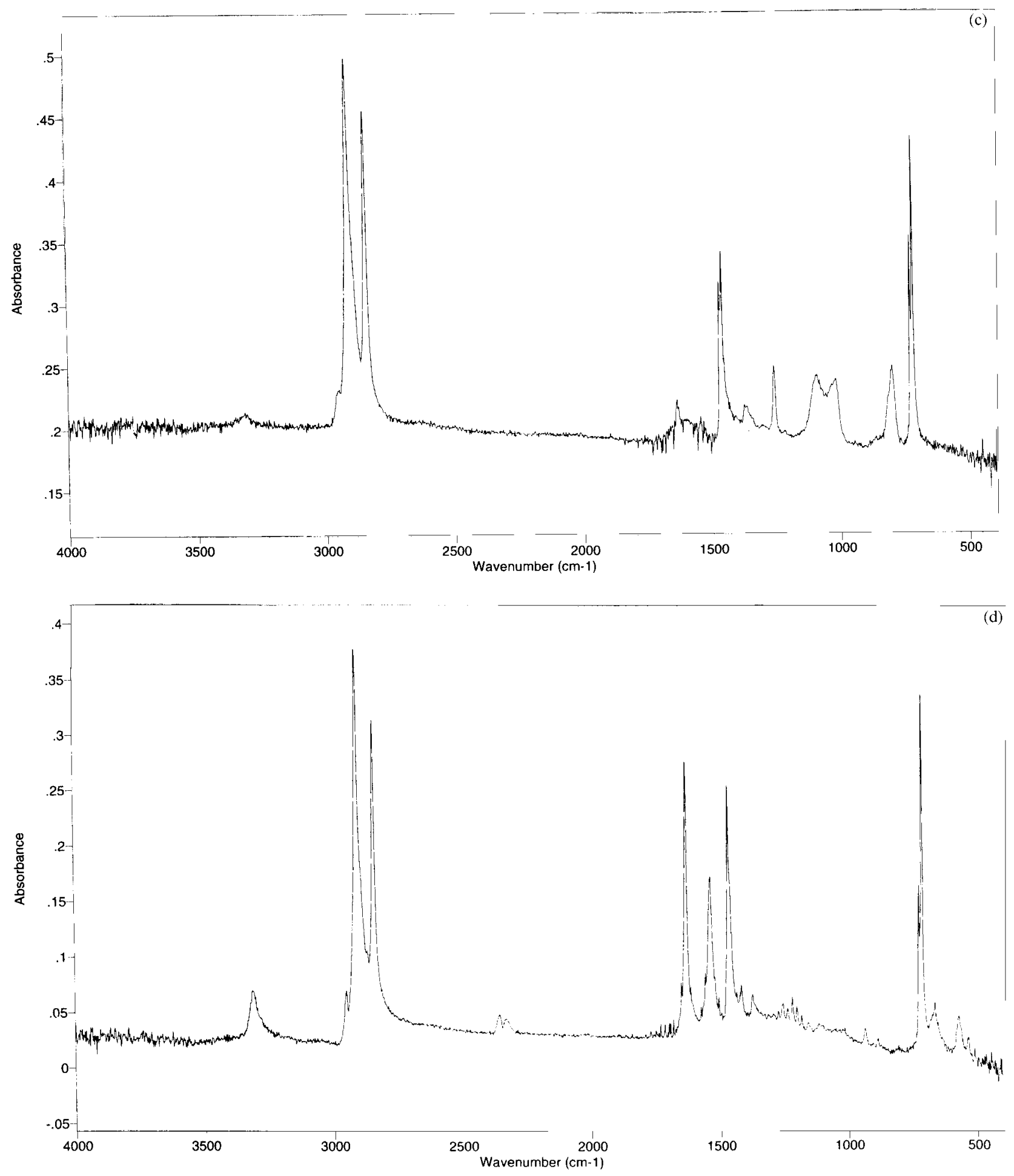

Figure 2 (Continued from the previous page)

what happens during and after heat treatment, the LDPE films were characterized by electron microscopy, infrared spectroscopy, and wideangle X-ray diffraction.

\section{Electron Microscopy}

An LDPE film with 5 wt \% stearyl stearamide and a thickness of $97 \pm 10 \mu \mathrm{m}$ was given a heat 
Table III Wavenumbers $k$ and Corresponding Vibrations of Peaks in the Spectra of Pure Components (LDPE and Stearyl Stearamide) Identified with ATR-IR

\begin{tabular}{llcc}
\hline$k\left(\mathrm{~cm}^{-1}\right)$ & Vibration & LDPE & $\begin{array}{c}\text { Stearyl } \\
\text { Stearamide }\end{array}$ \\
\hline 1450 & $\mathrm{C}-\mathrm{H}$ & $\mathrm{y}$ & $\mathrm{y}$ \\
1520,1620 & $\mathrm{C}=\mathrm{O} / \mathrm{C}-\mathrm{N}$ & & $\mathrm{y}$ \\
2830 & $\mathrm{C}-\mathrm{H}$ & $\mathrm{y}$ & $\mathrm{y}$ \\
2910 & $\mathrm{C}-\mathrm{H}$ & $\mathrm{y}$ & $\mathrm{y}$ \\
3300 & $\mathrm{~N}-\mathrm{H}$ & & $\mathrm{y}$ \\
\hline
\end{tabular}

Penetration depth $\leq 1.4 \mu \mathrm{m}$.

treatment for $1 \mathrm{~h}$ at $83^{\circ} \mathrm{C}$. By breaking the film in liquid nitrogen, a sample for scanning electron microscopy was prepared. The cross section was sputtered with gold. Figure 1 shows an electron microscope picture of the cross section of the LDPE film. In this picture, one can vaguely see a small layer at the top with an estimated thickness of 1-2 $\mu \mathrm{m}$. A similar layer can be observed at the bottom side of the film. This could indicate that the top and the bottom sides of the film contain other material than pure LDPE, resulting from a kind of phase separation during the heat treatment whereby the additive has migrated to both surfaces of the film. If, for simplicity, the values for the density of LDPE and stearyl stearamide are set equal, a maximum layer thickness of the additive of $5.0 \mu \mathrm{m}$ is expected. This confirms the idea that at a least a considerable fraction of the additive is present at the surface of the film.

\section{Attenuated Total Reflectance-Infrared Spectroscopy}

Electron microscopy revealed a layer present at an LDPE film blended with stearyl stearamide after heat treatment. With attenuated total reflectance-infrared spectroscopy (ATR-IR), one can characterize the surface of a sample. Absorption bands in the infrared spectrum are assigned to specific molecular vibrations, indicating, qualitatively, the kind of chemical groups at the surface. The penetration depth $d_{p}$ of the infrared beam into the sample depends on the wavelength $\lambda$ of the infrared beam, the refractive indices $n_{1}$ and $n_{2}$ of the crystal and the sample, respectively, and the angle of incidence $\theta$ of the infrared beam ${ }^{8}$ :

$$
d_{p}=\frac{\lambda}{2 \pi n_{1} \sqrt{\sin ^{2}(\theta)-\left(\frac{n_{2}}{n_{1}}\right)^{2}}}
$$

ATR-IR spectra of LDPE films were measured on a Biorad FTS-60. Peaks are in the region with wavenumbers larger than $1500 \mathrm{~cm}^{-1}$, which corresponds to a wavelength of $6.7 \mu \mathrm{m}$. The refractive index of the KRS-5 crystal is 2.37 and the refractive indices of polyethylene and stearyl stearamide are estimated to be 1.5. The angle of incidence is $45^{\circ}$. The maximum penetration depth will then be $1.4 \mu \mathrm{m}$. The layer thickness observed with the electron microscope is $1-2 \mu \mathrm{m}$, which is roughly equal to the penetration depth of the infrared beam. Therefore, the expected surface layers on heat-treated films can qualitatively be analyzed with this technique.

Figure 2 shows infrared spectra of four different samples: a pure LDPE film, a bar of pressed stearyl stearamide, an as-prepared LDPE film blended with $5 \mathrm{wt} \%$ stearyl stearamide, and a heat-treated LDPE film blended with 5 wt \% stearyl stearamide. In Table III, peaks that are present in the infrared spectra of Figure 2 (a) and (b), i.e., for LDPE and stearyl stearamide, respectively, are tabulated for those wavenumbers where the penetration depth of the infrared beam is about or less than $1.4 \mu \mathrm{m}$.

In the spectrum of LDPE, three peaks are identified resulting from $\mathrm{C}-\mathrm{H}$ vibrations, namely, at 2910, 2830, and $1450 \mathrm{~cm}^{-1}$. These absorption bands are also seen in the spectrum of stearyl stearamide due to the $\mathrm{C}-\mathrm{H}$ groups in its two fat tails. Additionally, one can observe in the spectrum of the additive vibrations of the $\mathrm{N}-\mathrm{H}$ bonds at $3300 \mathrm{~cm}^{-1}$ and of the $\mathrm{C}=\mathrm{O}$ and $\mathrm{C}-\mathrm{N}$ bonds at 1520 and $1620 \mathrm{~cm}^{-1}$. The spectrum of the asprepared film of LDPE blended with stearyl stearamide is almost similar to the spectrum of pure LDPE. Of course, there will be a small amount of the additive present near the surface of the film, but the peaks of the $\mathrm{N}-\mathrm{H}, \mathrm{C}=\mathrm{O}$, and $\mathrm{C}-\mathrm{N}$ bonds of stearyl stearamide are relatively small 
compared to the $\mathrm{C}-\mathrm{H}$ peaks. In the spectrum of the heat-treated LDPE film with stearyl stearamide, the $\mathrm{N}-\mathrm{H}, \mathrm{C}=\mathrm{O}$, and $\mathrm{C}-\mathrm{N}$ bonds are more pronounced and the spectrum resembles the spectrum of the pure stearyl stearamide, indicating that due to the heat treatment the additive has (partially) migrated to the surface of the LDPE film.

\section{Wide-angle X-ray Diffraction}

With wide-angle X-ray diffraction (WAXD), it is possible to investigate the ordening of a material. The characteristic distances in a crystal lattice or periodic structure are related to the angle of incidence by the Bragg equation ${ }^{9}$ :

$$
n \lambda=2 d \sin (\theta)
$$

with $n$ being an integer; $\lambda$, the wavelength of the $\mathrm{X}$-ray beam; $d$, a characteristic distance in a crystal lattice; and $\theta$, the angle of incidence of the Xray beam.

An importance difference compared to ATRIR is the penetration depth. With ATR-IR, the surface layer alone can be investigated. However, with WAXD, this is impossible. An identical set of samples as in the ATR-IR analysis has been analyzed with WAXD. In Figure 3, X-ray diffraction patterns are depicted of a pure LDPE film, a pressed bar of stearyl stearamide, an as-prepared LDPE film blended with 5 wt \% stearyl stearamide, and the corresponding heat-treated film.

The X-ray diffraction patterns of pure LDPE and of the as-prepared LDPE film are almost similar. The diffraction pattern of pure stearyl stearamide has three peaks at relatively large $d$-spacing which can be used to distinguish between LDPE and stearyl stearamide. The angles $2 \theta$ between the incident and reflected X-ray beam corresponding to the three peaks are $4.4^{\circ}, 6.2^{\circ}$, and $10.6^{\circ}$. The largest peak at $6.2^{\circ}$, although very weak, is also present in the diffraction pattern of the heattreated film. This indicates that some ordening of the additive occurs. Such an ordening can only take place when the amount of additive is locally increased compared to the film without heat treatment. The peak itself indicating this local ordening in Figure 3 is not very pronounced, but this is due how wide-angle x-ray diffraction evaluates the sample. With this technique, the whole sample is evaluated, while ordening of the additive only can be found in 5\% of the total sample. This observation indeed supports the hypothesis of phase separation after heat treatment which results in a layer of additive at the surface of the film with some ordening.

\section{DISCUSSION AND CONCLUSION}

In polymeric foam extrusion, low molecular weight additives can be used to improve the dimensional stability of the expanded product when the additive affects the permeabilities of blowing agent and air in such a way that they will be equal, i.e., the improved dimensional stability is accomplished by decreasing the permeability of the blowing agent while maintaining the air permeability at the same level.

Permeation experiments on polymer LDPE films with a varying amount of additive (stearyl stearamide) do show the desirable decrease in permeability of isobutane, only after a heat treatment was applied to the film. Time-lag experiments reveal that the diffusion coefficient of the blowing agent is affected by the presence of the additive. Similar results, but at a much larger time scale, have been obtained for mass transport of tributyl phosphate through polyethylene and polyurethane films in the presence of a small percentage of so-called film-forming additives. ${ }^{6}$

Results from different techniques presented in this article indicate that phase separation occurs, resulting in migration of the low molecular additive to the surface. Formation of a more or less structured layer of the additive at the surface can explain the low isobutane permeability. Ordening is considered to diminish permeability. ${ }^{5}$ The overall sorption in the heat-treated film is unaffected but the permeability decreases because permeation through the additive layer is diffusion-controlled. The diffusion coefficient of air is large compared the diffusion coefficient of isobutane and therefore the air permeability is hardly influenced by this stearyl stearamide layer.

This hypothesis can be applied to foam extrusion itself. Foam extrusion occurs at relatively high temperatures. Suppose that during such a heat treatment the additive migrates to the surface of the LDPE; then, the additive should also be present at all surfaces, external as well internal, of the extruded foam. An extruded foam has a large internal surface. To cover the complete surface of a foam with the additive, one can derive the following condition [eq. (6)] in which the lefthand side expresses the surface area per unit volume of foam assuming that the gas cells are spherical and the right-hand side expresses the area of 

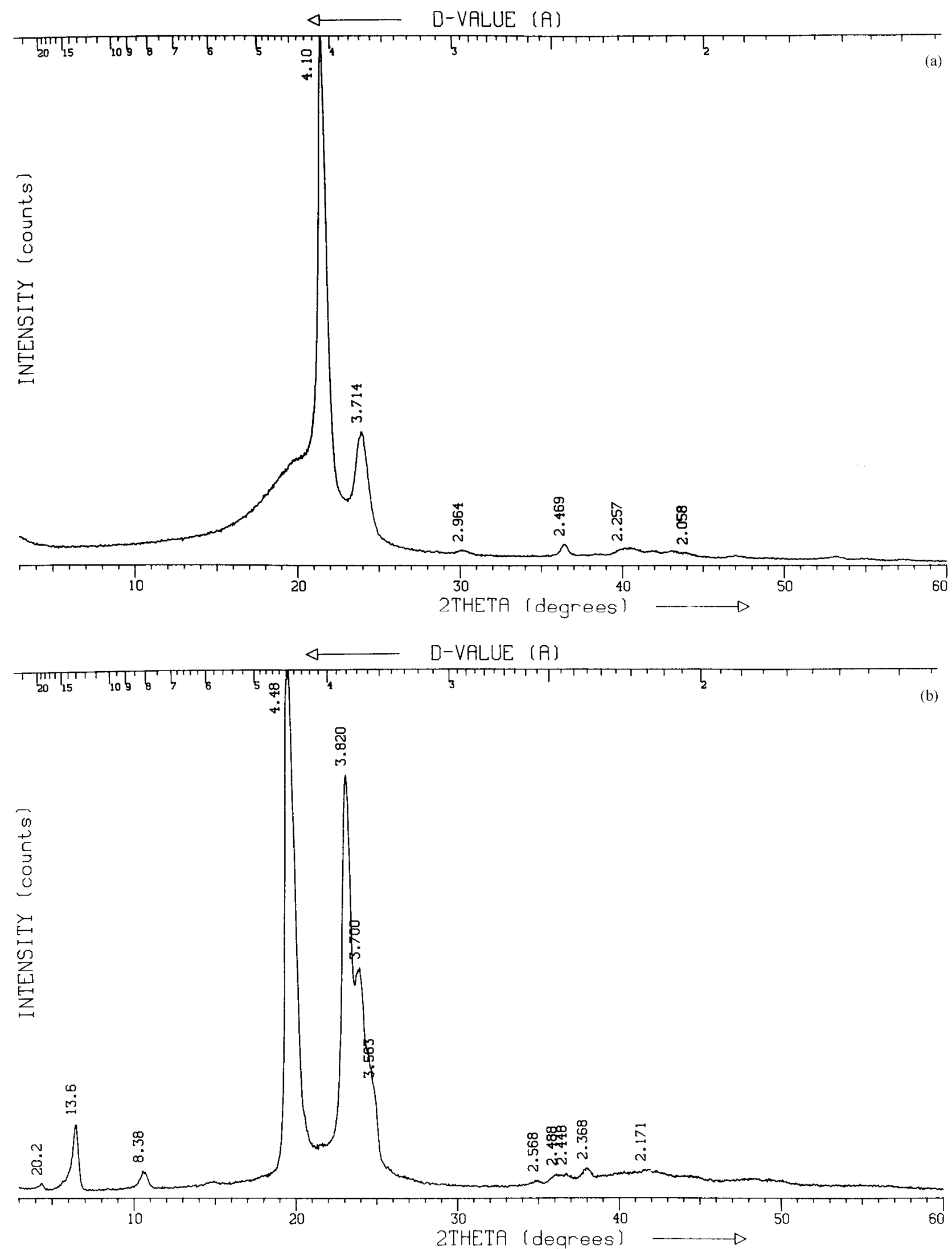

Figure 3 X-ray diffraction pattern of (a) an LDPE film, (b) a pressed stearyl stearamide bar, (c) an LDPE film blended with 5 wt \% stearyl stearamide, which has had no heat- 


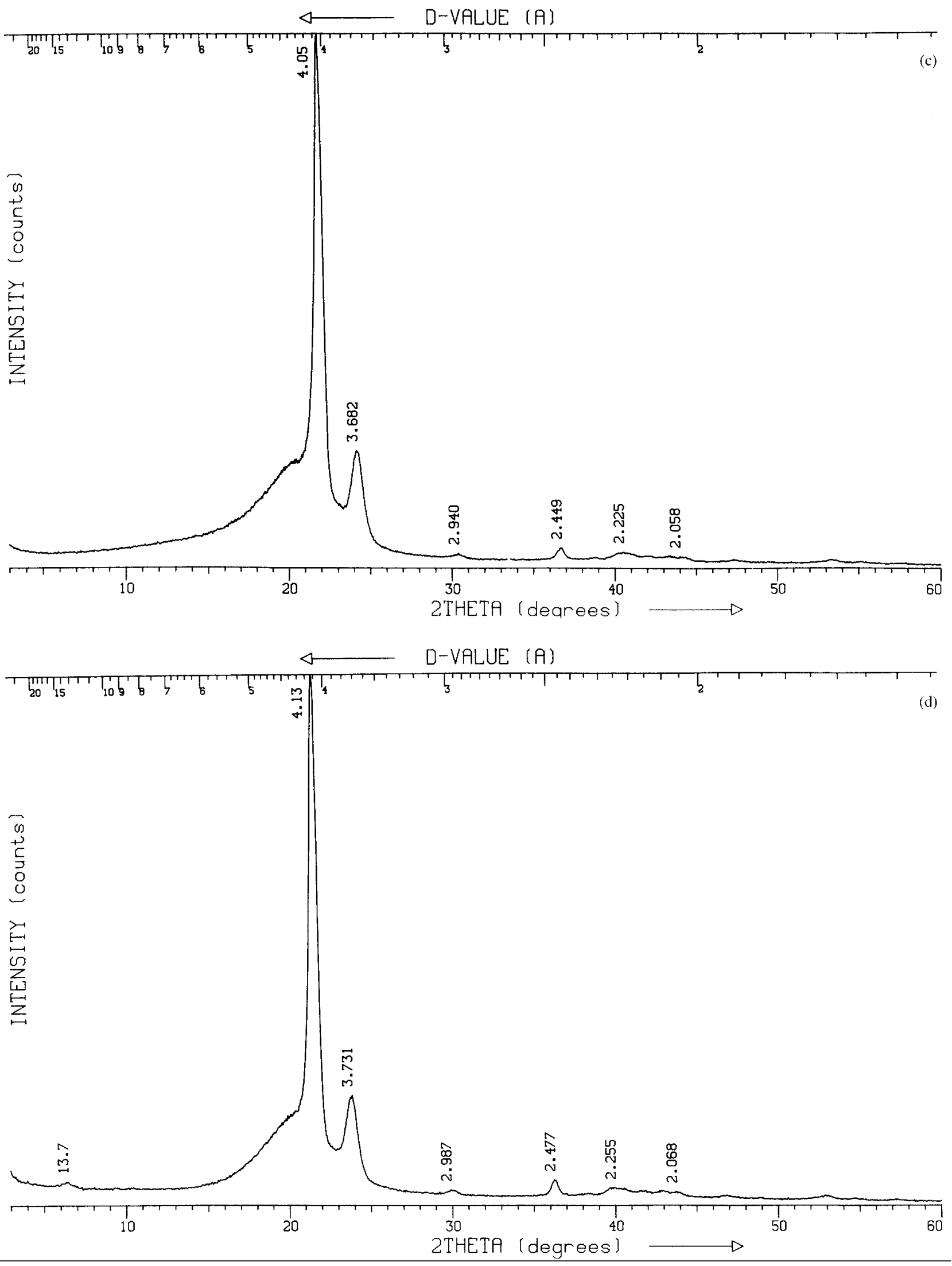

treatment, and (d) an LDPE film blended with 5 wt \% stearyl stearamide, which was heat treated for $1 \mathrm{~h}$ at $83^{\circ} \mathrm{C}$. 
a monolayer of the additive corresponding to the amount of additive per unit of foam volume:

$$
\begin{aligned}
& \frac{6}{d_{\text {cell }}} \times \frac{\rho_{\text {polymer }}-}{\rho_{\text {foam }}} \\
& \rho_{\text {polymer }}- \rho_{\text {gas }} \\
&<\frac{a w \rho_{\text {polymer }}}{M_{w}} \times \frac{\rho_{\text {foam }}-\rho_{\text {gas }}}{\rho_{\text {polymer }}-\rho_{\text {gas }}}
\end{aligned}
$$

In eq. ( 6 ), $\rho$ denotes the density; $d_{\text {cell }}$ is the diameter of a cell; $a$, the area occupied by one additive molecule; $w$, the weight fraction of additive with respect to the mass of additive and polymer; and $M_{w}$, the molecular weight of the additive. The polymer density is $921 \mathrm{~kg} \mathrm{~m}^{-3}$, the molecular weight of the additive $535.5 \mathrm{~g} \mathrm{~mol}^{-1}$, and the area $a$ is assumed to be of the same order as the area occupied by stearic acid which is $0.205 \mathrm{~nm}^{2} .{ }^{10}$

Blending the polymer with only a 1.5 wt $\%$ of stearyl stearamide is sufficient to cover the complete internal and external surfaces of a low density foam $\left(\rho=30-100 \mathrm{~kg} \mathrm{~m}^{-3}\right)$, when the cell diameter in the foam is larger than $100 \mu \mathrm{m}$. Although it is theoretically possible that all internal and external surfaces of commercial foams are covered with the additive, the presence of such a layer at the surfaces of these extruded foams cannot be confirmed with electron microscopy, ATRIR, or the WAXD technique.

It has been shown here that the additive is effective only when it is present at the surface of the film. The additive should be preferentially at the surfaces of the polymeric foam, i.e., the solubility of the additive in the polymer should be lower than the amount of blending. Furthermore, the additive should reach the surface within a short time compared to the time needed to exchange the blowing agent by air. This time depends on the diffusion coefficient of the additive in the polymer at the temperature of extrusion and it depends on the thickness of the polymeric layers that constitute the foam. As diffusion processes relate to each other with the square of film thickness, the latter condition is usually no problem, because the thicknesses of polymer layers in a cellular foam are, in general, of the order of 5 $\mu \mathrm{m}$ or less and cooling of foam is relatively slow. On the other hand, if the permeability is to be measured from relatively thick films blended with a certain amount of the additive, the heat treatment is essential in order to obtain the true permeabilities ( see Table I).

The permeability of the additive toward the blowing agent should be considerably lower than the corresponding polymer permeability. This can be accomplished by finding an additive with a low solubility and/or a low diffusion coefficient of the blowing agent. The additive in this work shows an ordening as has been revealed by WAXD experiments. Therefore, it can explain the low blowing agent permeability, because of the expected low diffusion coefficient and low solubility in this layer.

It is sufficient to measure the permeability of the pure additive in order to calculate an overall permeability. The ratio of total film thickness and overall permeability equals the summation over all layers of the ratio of a layer thickness and its corresponding permeability. The measurement of the permeability of pure additive is not easy, because it is difficult to obtain a coherent film that can withstand the pressure difference in a permeation experiment. Therefore, it is more convenient to measure the permeability in an indirect way, e.g., from a kinetic sorption experiment or in a permeation experiment with no hydrostatic pressure difference but only a partial pressure difference across the membrane. ${ }^{11}$

\section{NOMENCLATURE}

a area occupied by one molecule of additive $\left(\mathrm{m}^{2}\right)$

$d \quad$ characteristic distance in a periodic structure $(\mathrm{m})$

$d_{\text {cell }} \quad$ diameter of a cell in a foam ( $\mathrm{m}$ )

$d_{p} \quad$ penetration depth of infrared beam $(\mathrm{m})$

$k \quad$ wavenumber of infrared beam $\left(\mathrm{cm}^{-1}\right)$

$n \quad$ integer in the Bragg equation

$n_{1}, n_{2}$ refractive indices of crystal KRS-5 and sample, respectively

$p \quad$ pressure $(\mathrm{Pa})$

$t \quad$ time (s)

$w \quad$ weight fraction of additive

$q \quad$ angle of incidence of infrared or X-ray beam

$\lambda \quad$ wavelength of infrared or X-ray beam $(\mathrm{m})$ $\rho$ density $\left(\mathrm{kg} \mathrm{m}^{-3}\right)$

A film area available for permeation $\left(\mathrm{m}^{2}\right)$

$D \quad$ diffusion coefficient $\left(\mathrm{m}^{2} \mathrm{~s}^{-1}\right)$

$J \quad$ gas volume flux $\left[\mathrm{m}^{3}(\mathrm{STP}) \mathrm{m}^{-2} \mathrm{~s}^{-1}\right]$

$L \quad$ thickness of polymer film (m)

$M_{w} \quad$ molecular weight of additive $\left(\mathrm{kg} \mathrm{mol}^{-1}\right)$

$P \quad$ permeability $\left[\mathrm{m}^{3}(\mathrm{STP}) \mathrm{m} \mathrm{m}^{-2} \mathrm{~s}^{-1} \mathrm{~Pa}^{-1}\right.$ ]

$R \quad$ gas constant $\left(\mathrm{J} \mathrm{mol}^{-1} \mathrm{~K}^{-1}\right)$

$S \quad$ solubility $\left[\mathrm{m}^{3}(\mathrm{STP}) \mathrm{m}^{-3} \mathrm{~Pa}^{-1}\right.$ ]

$T$ absolute temperature (K)

$V_{c} \quad$ calibrated volume $\left(\mathrm{m}^{3}\right)$

$V_{m} \quad$ molar volume $\left[\mathrm{m}^{3}(\mathrm{STP}) \mathrm{mol}^{-1}\right]$ 


\section{REFERENCES}

1. C. P. Park, U.S. Pat. 4, 640,933 (1987).

2. D. Klempner and K. C. Frisch, Handbook of Polymeric Foams, Hanser, Munich, 1991.

3. R. H. B. Bouma, W. J. Nauta, J. E. F. Arnauts, Th. van den Boomgaard, J. M. Steuten, and H. Strathmann, to appear.

4. J. Crank, The Mathematics of Diffusion, Clarendon Press, Oxford, 1975, Chap. 4, § 3.

5. A. S. Michaels and H. J. Bixler, J. Polym. Sci., 50, 393-412, 413-439 (1961).
6. H. L. Frisch, A. Damusis, and H. C. Hsieh, J. Membr. Sci., 17, 255-261 (1984).

7. H. L. Frisch, J. Membr. Sci., 13, 151-159 (1983).

8. P. R. Griffiths and J. A. de Haseth, Fourier Transform Infrared Spectrometry, Wiley, New York, Chap. 5, § 3 .

9. H. Ibach and H. Lüth, Festkörperphysik, SpringerVerlag, Berlin, 1981, Chap. 3, § 4.

10. A. W. Adamson, Physical Chemistry of Surfaces, Wiley, New York, Chap. 11, § 4.

11. I. Greener Donhowe and O. Fennema, J. Am. Oil Chem. Soc., 70, 867-873 (1993). 